\title{
Aplikasi Mobile Learning Berbasis Web Service Menggunakan Sistem Operasi Android (Studi Kasus Fakultas Teknik Elektronika dan Komputer UKSW)
}

\author{
Acip Susman Alyahi ${ }^{1}$, Saptadi Nugroho², Darmawan Utomo ${ }^{3}$ \\ ${ }^{1}$ Program Studi Teknik Elektro, \\ Fakultas Teknik Elektronika dan Komputer \\ Universitas Kristen Satya Wacana, Salatiga \\ 1acip.susman.alyahi@gmail.com \\ 2,3Program Studi Sistem Komputer, \\ Fakultas Teknik Elektronika dan Komputer, \\ Universitas Kristen Satya Wacana, Salatiga \\ ${ }^{2}$ saptadi_nugroho@yahoo.com, ${ }^{3}$ darmawan@staff.uksw.edu
}

\begin{abstract}
Ringkasan
Pada makalah ini akan dijelaskan perancangan sebuah aplikasi Android yang dapat menambah fleksibilitas kegiatan belajar mengajar antara pengajar dan pelajar selain harus berada di dalam kelas. Dengan aplikasi ini pengajar yang dalam hal ini dosen atau asisten dosen dapat membuat materi, perintah tugas, dan pengumuman yang dapat dilihat oleh pengguna yang terdaftar dalam database server aplikasi tersebut. Aplikasi ini bekerja dengan menggunakan web service dengan mengakses data pada suatu web server dalam format Java Script Object Notation (JSON). Berdasarkan dari pengujian unit yang dilakukan didapatkan hasil aplikasi dapat berjalan $100 \%$. Format JSON menjadi salah satu alternatif media web service sebagai pertukaran data karena memiliki ukuran data yang lebih ramping sehingga kecepatan loading transfer datanya lebih cepat dibandingkan dengan format XML. Aplikasi ini dapat berjalan di sistem operasi Android versi 4.0.3 dan diatasnya.
\end{abstract}

Kata kunci: Mobile Learning, Android, Web Service

\section{Pendahuluan}

Perkembangan teknologi yang sangat cepat membuat pemanfaatan teknologi mobile juga turut berkembang semakin luas. Teknologi mobile yang sebelumnya hanya digunakan sebagai media komunikasi dan hiburan saja, kini bertambah manfaatnya sebagai media pembelajaran. Istilah Mobile Learning pun ikut mencuat sebagai bagian dari e-Learning [1]. Mobile Learning merupakan proses belajar di berbagai konteks, melalui interaksi sosial dan konten, menggunakan perangkat elektronik pribadi [2]. Penggunaan media portable menjadi salah satu keunggulan dari pembelajaran mobile learning dimana mobile learning dapat menambah fleksibilitas dalam kegiatan belajar mengajar di dalam kelas [3]. Namun model pembelajaran mobile learning ini masih belum dimanfaatkan secara maksimal oleh pihak atau instansi pendidikan, padahal mobile learning dapat dijadikan sebagai salah satu sarana belajar mandiri yang efektif bagi para pelajar dimana 
pelajar dapat dengan leluasa mengakses materi-materi yang tersedia. Berdasarkan permasalahan tersebut, telah dibuat sebuah aplikasi mobile yang dapat membantu proses pembelajaran di Fakultas Teknik Elektronika dan Komputer Universitas Kristen Satya Wacana.

\section{Perancangan Sistem}

Pada sistem yang dibuat ini terbagi menjadi dua yaitu aplikasi mobile dan aplikasi web server. Aplikasi mobile digunakan oleh pengguna bertipe dosen dan mahasiswa, sedangkan aplikasi web server digunakan oleh pengguna bertipe administrator. Aplikasi mobile dijalankan menggunakan smartphone Android, sedangkan aplikasi web server diakses dengan menggunakan Chrome web browser.

\subsection{Aplikasi Mobile}

Dalam aplikasi mobile terdapat dua pengguna yaitu dosen dan mahasiswa. Pengguna bertipe mahasiswa dapat memiliki hak sebagai asisten dosen yang diatur di dalam aplikasi web server. Semua pengguna dapat melihat semua materi yang ada. Pengguna bertipe dosen dan mahasiswa yang memiliki hak asisten dosen dapat membuat materi, perintah tugas, dan pengumuman yang berkaitan dengan kegiatan belajar mengajar. Pengguna bertipe mahasiswa hanya dapat melihat pengumuman dan tugas berdasarkan matakuliah yang diambil oleh mahasiswa tersebut. Use case untuk dosen menggunakan aplikasi mobile dapat dilihat pada Gambar 1 dan use case untuk mahasiswa dapat dilihat pada Gambar 2 dan Gambar 3.

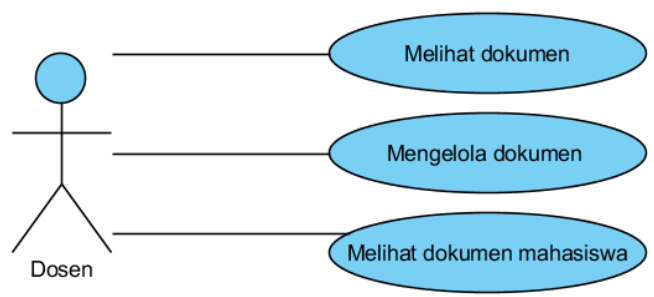

Gambar 1. Use Case Dosen Aplikasi Mobile

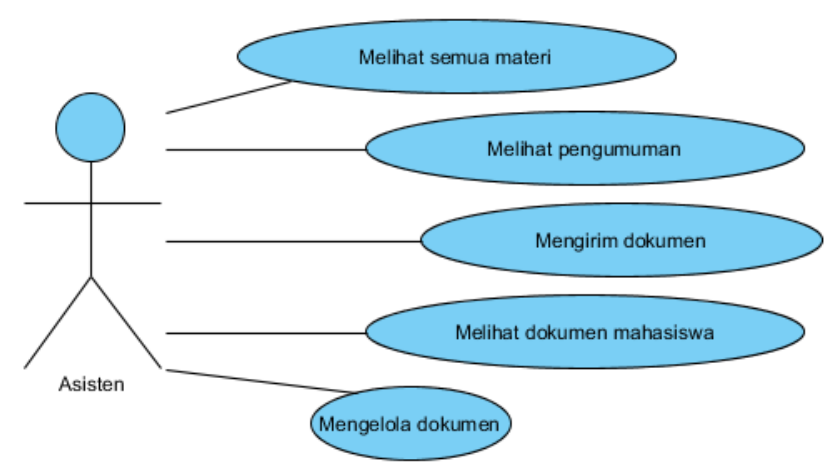

Gambar 2. Use Case Mahasiswa dengan Hak asisten Aplikasi Mobile 


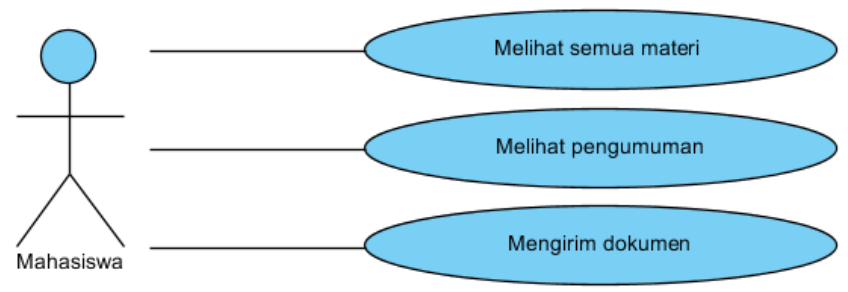

Gambar 3. Use Case Mahasiswa tanpa Hak Asisten Aplikasi Mobile

Diagram alir aplikasi mobile learning dapat dilihat pada Gambar 4.

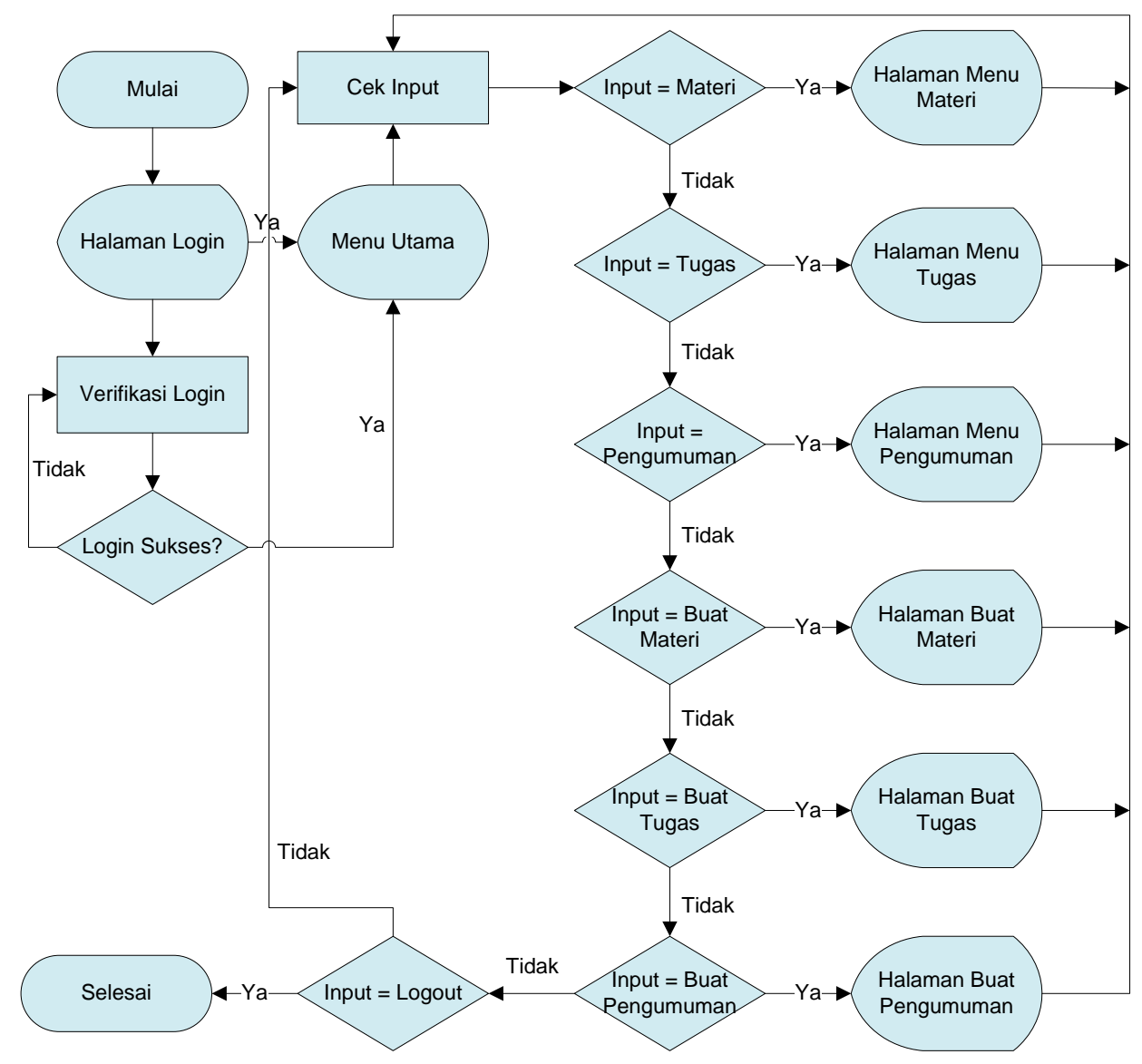

Gambar 4. Diagram Alir Aplikasi Mobile Learning

\subsection{Aplikasi Web Server}

Dalam aplikasi web server terdiri dari dua bagian yaitu aplikasi administrator dan aplikasi e-learning. Aplikasi administrator lebih fokus menangani manajemen data - data yang akan mengalami perubahan secara berkala maupun dalam kondisi mendesak. Data - data yang ditangani di aplikasi ini seperti data dosen, data mahasiswa, data matakuliah, data registrasi matakuliah, dan data kegiatan belajar mengajar. Use case untuk administrator menggunakan aplikasi web server dapat dilihat pada Gambar 5 . 


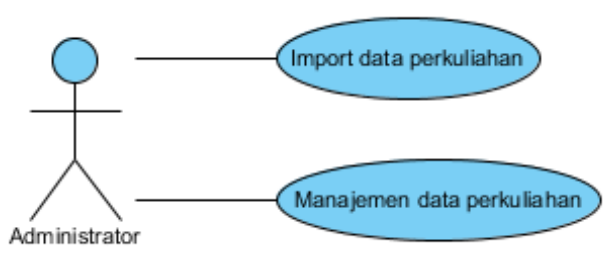

Gambar 5. Use Case Administrator

Diagram alir aplikasi administrator dapat dilihat pada Gambar 6.

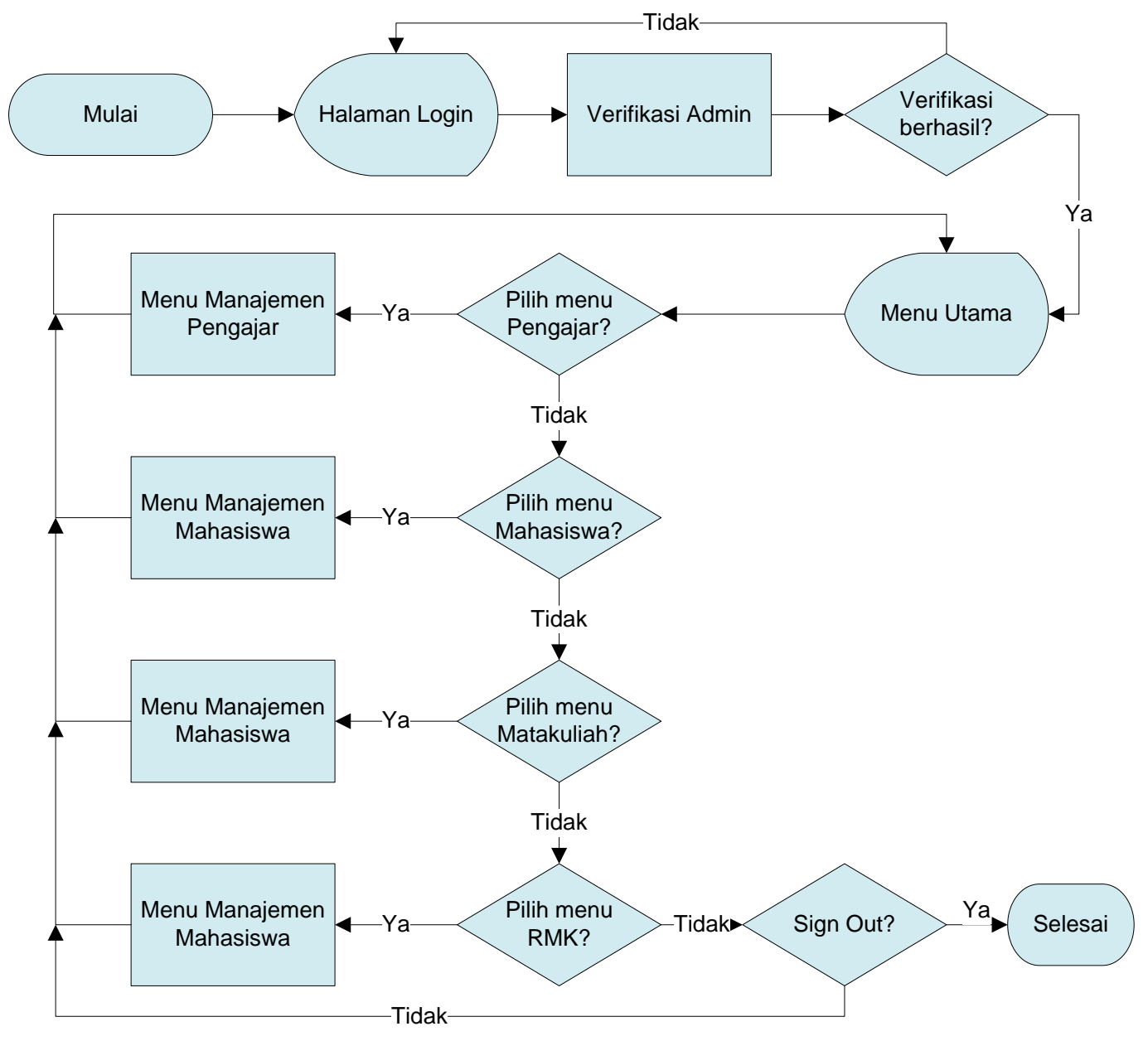

Gambar 6. Diagram Alir Aplikasi Administrator

Aplikasi e-learning secara fungsi memiliki kesamaan dengan aplikasi mobile. Aplikasi ini bertujuan untuk menutup kekurangan yang ada pada aplikasi mobile, misalnya pengguna akan lebih mudah membuat materi yang kompleks dengan komputer dibandingkan dengan smartphone.

\subsection{Desain Arsitektur Sistem}

Sistem yang dibangun terdiri dari aplikasi mobile sebagai client untuk menampilkan informasi seperti data produk dan aplikasi web server yang menyediakan informasi ke client. Arsitektur dari sistem dapat dilihat pada gambar 7. 


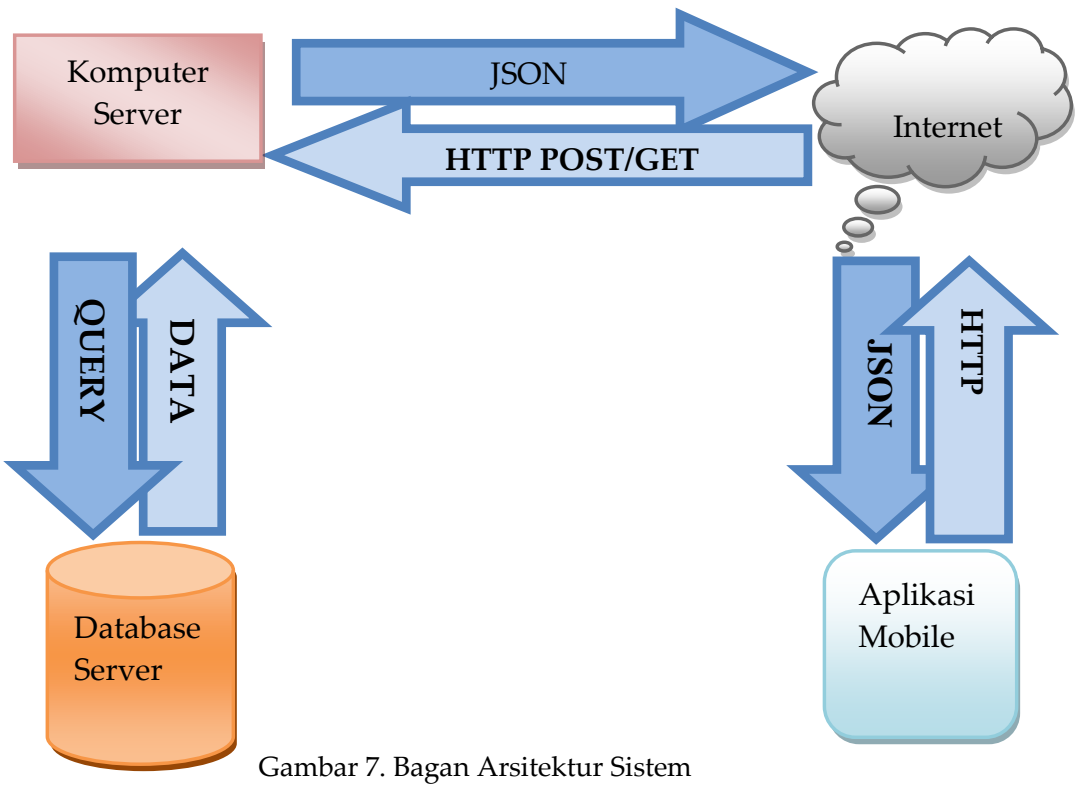

Penjelasan dari arsitektur adalah sebagai berikut:

1. Web Server

Aplikasi ini bertugas mengatur data pengguna, materi, pengumuman, dan lain sebagainya dimana data tersebut disimpan dalam database server. Selain itu aplikasi ini bertugas juga sebagai server web service untuk menerima permintaan dari client melalui HTTP POST atau HTTP GET untuk diolah dan mengirimkan hasilnya kembali ke client dalam format JSON.

2. Database Server

Database server bertugas sebagai media penyimpanan data pengguna, materi, pengumuman, dan lain sebagainya.

3. Aplikasi Mobile

Aplikasi mobile adalah aplikasi client yang digunakan oleh pengguna untuk menampilkan informasi. Data dan informasi mengenai materi, tugas, pengumuman dan lain sebagainya didapat dari web server.

\subsection{Perancangan Database}

Database yang digunakan pada aplikasi web server adalah MySQL. Entity Relationship Diagram (ERD) pada database server ditunjukkan pada Gambar 8. 


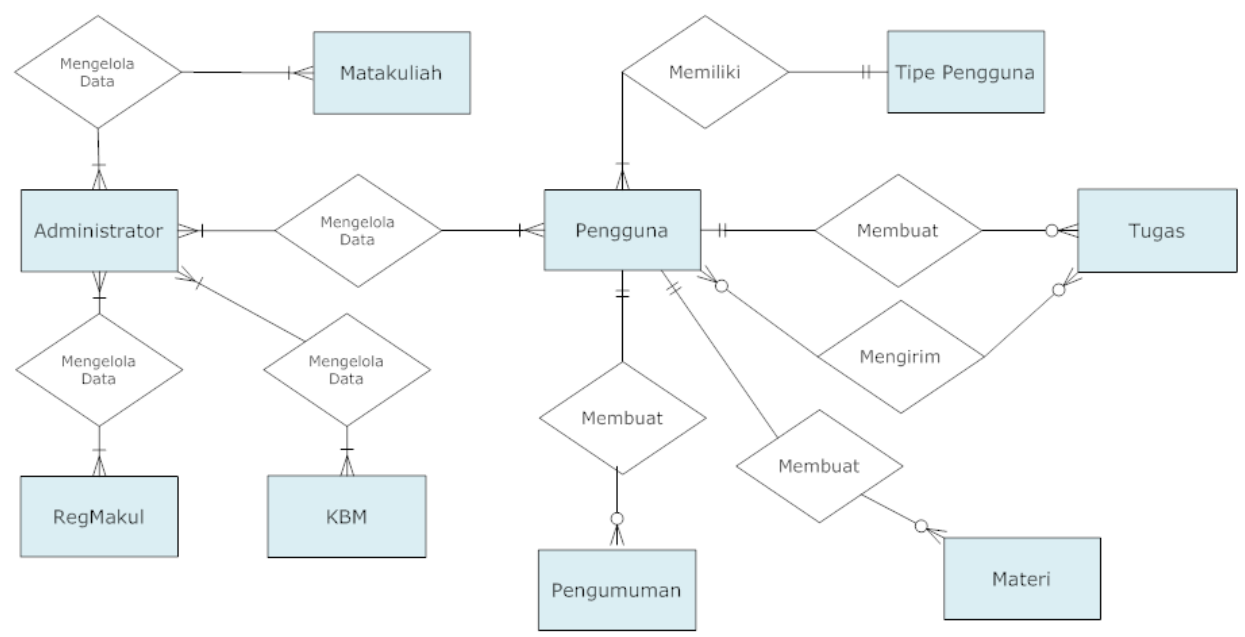

Gambar 8. Entity Relationship Diagram Database Server

Tabel Administrator digunakan untuk menyimpan informasi pengguna administrator. Tabel Pengguna digunakan untuk menyimpan informasi pengguna client. Tabel Tipe Pengguna digunakan untuk informasi macam - macam tipe pengguna client. Tabel Matakuliah digunakan untuk menyimpan informasi matakuliah. Tabel Materi digunakan untuk menyimpan data materi. Tabel Tugas digunakan untuk menyimpan informasi perintah tugas. Tabel Pengumuman digunakan untuk menyimpan informasi pengumuman, tabel KBM digunakan untuk menyimpan informasi kegiatan belajar mengajar di kelas dan tabel RegMakul yang berisi informasi registrasi matakuliah mahasiswa.

\section{Pengujian}

Pengujian unit ini dilakukan dalam tahap pengembangan aplikasi. Pengujian dilakukan terhadap komponen atau class pada aplikasi untuk memeriksa bahwa komponen atau class dapat digunakan dan menghasilkan hasil yang diharapkan. Pengujian unit dilakukan pada aplikasi web server dan aplikasi android.

\subsection{Pengujian Unit Aplikasi Web Server}

Proses pengujian unit pada aplikasi web server dibantu dengan bantuan API Toast yaitu controller khusus untuk menangani pengujian unit pada codeigniter. Pengujian dilakukan terhadap class model antara lain model admin_model, user_model, news_model,rmk_model, task_model, thread_model, dan category_model.

Prosedur pengujian yang dilakukan yaitu dengan menguji unit/class pada aplikasi web server dengan menggunakan bantuan API Toast yang telah ditanamkan pada aplikasi web server. Pengujian dijalankan dengan menggunakan skenario antara lain:

a. Menguji class apakah dapat berjalan tanpa ada kesalahan/ error atau bug.

b. Menguji class apakah dapat menghasilkan nilai yang diharapkan sesuai dengan skenario.

Jika pengujian berhasil maka class dinyatakan lolos/passed yang ditandai dengan warna hijau. Dan jika gagal maka class dinyatakn tidak lolos/not passed yang ditandai dengan warna merah. Contoh hasil pengujian unit pada aplikasi web server dapat dilihat pada Gambar 9. 
Toast Unit Tests:

\begin{tabular}{ll|} 
1. & [PASSED] test_news_model $\rightarrow$ news_model \\
2. & [PASSED] test_news_model $\rightarrow$ getNews \\
3. & [PASSED] test_news_model $\rightarrow$ getTotalNews \\
4. & [PASSED] test_news_model $\rightarrow$ getNewsWeb \\
5. & [PASSED] test_news_model $\rightarrow$ getMyNews \\
6. & [PASSED] test_news_model $\rightarrow$ getMyNNewsWeb \\
7. & [PASSED] test_news_model $\rightarrow$ getNewsData \\
8. & [PASSED] test_news_model $\rightarrow$ saveNews \\
\hline 9. & [PASSED] test_news_model $\rightarrow$ insertNews \\
\hline 0. & [PASSED] test_news_model $\rightarrow$ deleteNews
\end{tabular}

All tests completed in 0.4360 seconds

Gambar 9. Pengujian Unit Class news_model pada Aplikasi Web Server

Hasil pengujian unit pada aplikasi web server dapat dilihat pada Tabel 1.

Tabel 1. Hasil Pengujian Unit Aplikasi Web server

\begin{tabular}{|c|c|c|c|c|}
\hline No & Nama Unit & $\begin{array}{c}\text { Jumlah } \\
\text { Skenario }\end{array}$ & $\begin{array}{c}\text { Jumlah Tes } \\
\text { Berhasil }\end{array}$ & $\begin{array}{c}\text { Persentase } \\
\text { Keberhasilan }\end{array}$ \\
\hline 1 & test_admin_model & 1 & 1 & $100 \%$ \\
\hline 2 & test_user_model & 18 & 18 & $100 \%$ \\
\hline 3 & test_category_model & 14 & 14 & $100 \%$ \\
\hline 4 & test_thread_model & 31 & 31 & $100 \%$ \\
\hline 5 & test_task_model & 15 & 15 & $100 \%$ \\
\hline 6 & test_news_model & 9 & 9 & $100 \%$ \\
\hline 7 & test_rmk_model & 1 & 1 & $100 \%$ \\
\hline & Total & 89 & 89 & $100 \%$ \\
\hline
\end{tabular}

\subsection{Pengujian Unit Aplikasi Mobile}

Pada aplikasi mobile, android sudah menyediakan library android.test.ActivityInstrumentationTestCase2 untuk membantu proses pengujian unit. Pengujian unit dilakukan terhadap semua activity class. Prosedur pengujian yang dilakukan yaitu dengan menguji activity class pada aplikasi mobile dengan menggunakan bantuan android.test.ActivityInstrumentation TestCase2. Pengujian dijalankan dengan menggunakan skenario antara lain:

a. Menguji class apakah dapat berjalan tanpa ada kesalahan/ error atau bug.

b. Menguji class activity komponen user interface seperti button, dan text form dapat berjalan dengan baik.

Jika pengujian berhasil maka class dinyatakan lolos/ passed yang ditandai dengan warna hijau. Dan jika gagal maka class dinyatakan tidak lolos/ not passed yang ditandai dengan warna merah. Contoh hasil pengujian unit pada aplikasi mobile dapat dilihat pada Gambar 10. 
Techné Jurnal Ilmiah Elektroteknika Vol. 14 No. 2 Oktober 2015 Hal. 137 - 146

\begin{tabular}{|l|l|l|}
\multicolumn{1}{c|}{ Test $\_$} & \multicolumn{1}{c}{ Time elapsed } & Results \\
\hline testActivityExists & $1.377 \mathrm{~s}$ & Passed \\
\hline test_btCreateNews & $0.626 \mathrm{~s}$ & Passed \\
\hline test_btCreateTask & $0.3 \mathrm{~s}$ & Passed \\
\hline test_btCreateThread & $0.225 \mathrm{~s}$ & Passed \\
\hline test_btQuick & $0.225 \mathrm{~s}$ & \\
\hline
\end{tabular}

Gambar 10. Pengujian Unit Class MainActivity pada Aplikasi Mobile

Hasil pengujian unit pada aplikasi mobile dapat dilihat pada Tabel 2.

Tabel 2. Hasil Pengujian Unit Aplikasi Mobile

\begin{tabular}{|c|c|c|c|c|}
\hline No & Nama Unit & $\begin{array}{l}\text { Jumlah } \\
\text { Skenario }\end{array}$ & $\begin{array}{c}\text { Jumlah Tes } \\
\text { Berhasil }\end{array}$ & $\begin{array}{c}\text { Persentase } \\
\text { Keberhasilan }\end{array}$ \\
\hline 1 & MainActivity & 5 & 5 & $100 \%$ \\
\hline 2 & CreateThreadActivity & 4 & 4 & $100 \%$ \\
\hline 3 & CreateTaskActivity & 9 & 9 & $100 \%$ \\
\hline 4 & CreateNewsActivity & 6 & 6 & $100 \%$ \\
\hline 5 & DraftActivity & 4 & 4 & $100 \%$ \\
\hline 6 & DraftListActivity & 3 & 3 & $100 \%$ \\
\hline 7 & EditNewsActivity & 4 & 4 & $100 \%$ \\
\hline 8 & EditstepActivity & 7 & 7 & $100 \%$ \\
\hline 9 & EditTaskActivity & 9 & 9 & $100 \%$ \\
\hline 10 & FullscreenImageActivity & 1 & 1 & $100 \%$ \\
\hline 11 & IntroActivity & 7 & 7 & $100 \%$ \\
\hline 12 & LoginActivity & 4 & 4 & $100 \%$ \\
\hline 13 & MateriListActivity & 3 & 3 & $100 \%$ \\
\hline 14 & NewsListActivity & 3 & 3 & $100 \%$ \\
\hline 15 & TaskListActivity & 3 & 3 & $100 \%$ \\
\hline 16 & OverviewActivity & 4 & 4 & $100 \%$ \\
\hline 17 & PhotoProfileActivity & 3 & 3 & $100 \%$ \\
\hline 18 & PreviewActivity & 3 & 3 & $100 \%$ \\
\hline 19 & PublishActivity & 2 & 2 & $100 \%$ \\
\hline 20 & TaskDetailActivity & 5 & 5 & $100 \%$ \\
\hline 21 & ThreadActivity & 4 & 4 & $100 \%$ \\
\hline 22 & ViewVideoActivity & 1 & 1 & $100 \%$ \\
\hline & Total & 94 & 94 & $100 \%$ \\
\hline
\end{tabular}

Pada pengujian unit didapat hasil aplikasi dapat berjalan $100 \%$ atau dapat lolos dari semua skenario pengujian.

\subsection{Pengujian Web Service}

Pada pengujian ini dilakukan pengukuran besar data web service dalam byte dan juga membandingkan besar data JSON dengan XML. Perbandingan dilakukan untuk meneliti tingkat efisiensi besar data antara JSON dengan XML. Pengujian dilakukan dengan mengambil sampel data matakuliah dengan jumlah data yang divariasikan. Untuk mengetahui besar data pengiriman data dengan JSON dan perbandingannya dengan XML dapat dilihat pada Tabel 3. 
Tabel 3. Perbandingan Besar Data JSON dan XML

\begin{tabular}{|c|c|c|c|c|}
\hline \multirow{2}{*}{ No } & Jumlah Data Matakuliah & \multicolumn{2}{|c|}{ Besar Data (Byte) } & $\begin{array}{c}\text { Perbandingan } \\
\boldsymbol{X} \boldsymbol{M} \boldsymbol{L}\end{array}$ \\
\cline { 3 - 4 } & & JSON & XML & $\frac{\boldsymbol{J S O N}}{1,706}$ \\
\hline 1 & 5 & 508 & 867 & 1,646 \\
\hline 2 & 10 & 1002 & 1650 & 1,689 \\
\hline 3 & 20 & 1930 & 3260 & 1.69 \\
\hline 4 & 35 & 3350 & 5660 & 1.712 \\
\hline Total & 50 & 4770 & 8170 & 8.443 \\
\hline Rata-Rata & 120 & 11560 & 19607 & 1.688 \\
\hline
\end{tabular}

Pada pengujian di atas dilakukan pengukuran besar data JSON dan XML dengan jumlah data yang akan dikirimkan sebanyak 5 hingga 50 buah. Untuk 50 buah data, JSON mempunyai besar 4,77 kilobyte sedangkan XML sebesar 8,17 kilobyte . Rata-rata perbandingan besar data JSON dengan XML adalah 1:1,688. Dapat disimpulkan bahwa JSON mampu membawa data dengan ukuran yang lebih sedikit dibandingkan dengan XML. Hal ini karena JSON tidak menuliskan tag element data sebanyak dua kali sama seperti XML sehingga mampu menghemat ukuran data.

\subsection{Pengujian Resolusi Layar Aplikasi Mobile}

Pengujian dilakukan dengan menggunakan dua buah perangkat yang memiliki layar cukup jauh berbeda yaitu Samsung Galaxy Tab 3 Lite yang memiliki ukuran layar 7 inci dan Xiaomi Mi4i yang ukuran layarnya 5 inci. Pengujian tampilan layar kedua perangkat tersebut ditunjukkan pada Gambar 11.

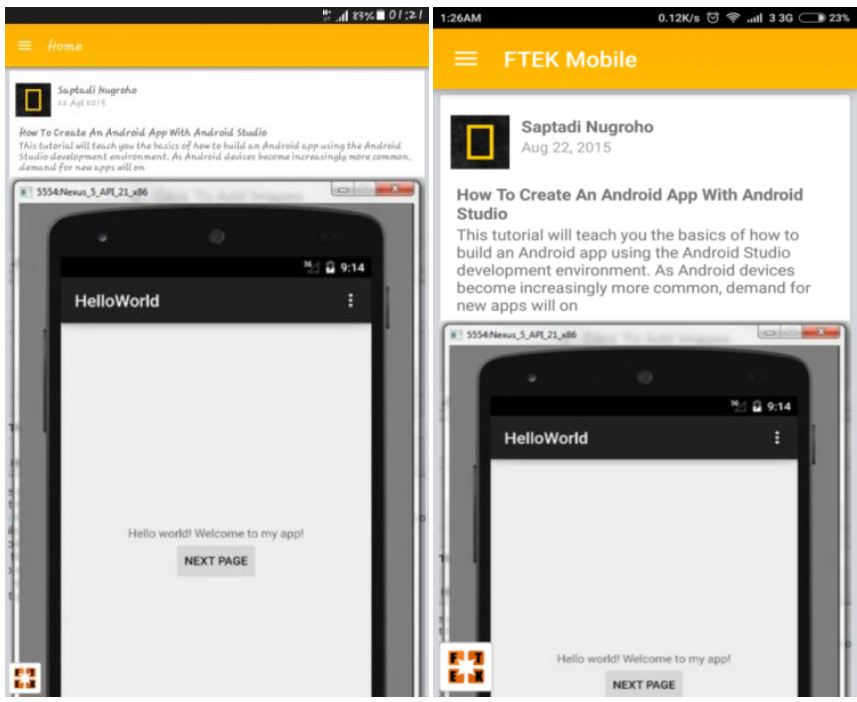

Gambar 11. Pengujian Tampilan Aplikasi Mobile dengan Perangkat Berlayar 7 inci (Gambar Kiri) dan Perangkat berlayar 5 inci (Gambar Kanan)

Dari pengujian layar dapat dikatakan perangkat berlayar 5 inci memberikan tampilan yang lebih baik daripada perangkat yang berlayar 7 inci. Semakin besar ukuran layar perangkat maka kualitas tampilan yang akan diberikan akan semakin berkurang. 


\section{Kesimpulan}

Berdasarkan pengujian dari sistem aplikasi mobile learning ini dapat disimpulkan aplikasi dapat berjalan $100 \%$ sesuai dengan pengujian menggunakan pengujian unit. Data yang digunakan pada aplikasi ini lebih baik menggunakan format JSON karena mampu membawa data dengan ukuran yang lebih sedikit dibandingkan format XML dengan perbandingan besar data antara JSON dengan XML 1:1,688. Ukuran layar dari perangkat menentukan kualitas dari tampilan aplikasi ini, semakin besar ukuran layar perangkat maka kualitas tampilan yang akan diberikan akan semakin berkurang.

\section{Daftar Pustaka}

[1] M. Sarrab, L. Elgamel, dan H. Aldabbas, Mobile Learning (M-Learning) and Educational Environments, International Journal of Distributed and Parallel Systems, 4, 3, 31, 2012.

[2] H. Crompton, A historical overview of mobile learning: Toward learner-centered education. In Z. L. Berge \& L. Y. Muilenburg (Eds.), Handbook of mobile learning (hal. 3-14). Florence, KY: Routledge, 2013.

[3] Jin, Yi., Research of One Mobile Learning System, International Conference on Wireless Networks and Information Systems, Shanghai, Desember 2009. 